Available online at www.eccomasproceedia.org

Eccomas Proceedia COMPDYN (2021) 614-625

ECCOMAS

$8^{\text {th }}$ ECCOMAS Thematic Conference on

Proceedia Computational Methods in Structural Dynamics and Earthquake Engineering M. Papadrakakis, M. Fragiadakis (eds.)

Streamed from Athens, Greece, 28 - 30 June 2021

\title{
HORIZONTAL FORCE CAPACITY OF A HEMI-SPHERICAL DOME
}

\author{
Carlo Olivieri $^{1}$, Anna Castellano ${ }^{2}$, Isabella Elia ${ }^{2}$, Antonio Fortunato ${ }^{1}$, Ida Mascolo ${ }^{1}$ \\ ${ }^{1}$ University of Salerno, \\ Department of Civil Engineering, \\ Fisciano (SA), Italy e-mail: colivieri,a.fortunato,i.mascolo\}@unisa.it \\ ${ }^{2}$ Polytechnic University of Bari, \\ Department of Civil Engineering Sciences and Architecture, \\ Bari, Italy \\ e-mail: \{anna.castellano, isabella.elia\}@poliba.it
}

\begin{abstract}
The assessment of the ultimate load capacity of masonry domes and vaults is a complex open issue of both professional and research concern. 3D curved geometry of such structures entails biaxial stress states and highly nonlinear mechanical behaviors which require advanced computational strategies to be rigorously dealt with.

This study focuses on the assessment of the capacity of masonry hemispherical domes subjected to horizontal forces (such as those produced by wind and earthquake). In the framework of Limit Analysis (LA), a parametric Membrane Equilibrium Analysis (MEA) is proposed based on No-Tension (NT) material assumptions in the sense of Heyman: the unilateral membrane must lay inside the boundary surfaces of the dome and the membrane stress must have a non-positive concave potential. The membrane equilibrium problem for the dome is then formulated in Pucher form and controlled by a few parameters to be optimized. Two elementary examples are also provided to illustrate the method.
\end{abstract}

Keywords: Masonry, No-Tension materials, Membrane Equilibrium Analysis, Domes, Horizontal loads, parametric analysis, compressed shells.

ISSN:2623-3347 C 2021 The Authors. Published by Eccomas Proceedia. Peer-review under responsibility of the organizing committee of COMPDYN 2021. doi:10.7712/120121.8513.19613 


\section{INTRODUCTION}

The assessment of the structural capacity under horizontal forces (e.g., wind, inertial forces induced by earthquake etc.) of masonry domes or vaults is a challenging issue of structural engineering of relevant practical importance [1]-[9]. This is a very complicated problem, due to the interaction between biaxial stress on curved geometries and the highly non-linear mechanical behavior of masonry material. A number of researchers over the years have tried to develop complex Finite or Discrete Element (FEM, DEM) numerical strategies, often with very sophisticated material models mimicking the actual properties of masonry (such as anisotropy, plasticity, viscosity, damage and degradation processes, non-linear behavior etc.) in some detail. The precision and the accuracy of these models depend on the amount and quality of geometric and mechanical data used for the simulations [10]-[17]. However, the number of uncertainties and randomness related to the definition of such geometric and mechanical parameters make it arduous, not to say impossible, to draw definite and correct masonry models. This observation opened the way to a number of experimental approaches based, for example, on tilting tests on scale models [18]-[21].

Many papers have appeared in recent years setting a new promising approach in the framework of Limit Analysis, based on the application of the static and kinematic theorems to admissible stress and strain fields [22]-[31]. They exploit the unilateral masonrylike material model, also known as No-Tension (NT) model, dating back to the pioniering works of Heyman [32] and Zienkiewicz [33]. The key advantage of such approach is that no mechanical properties are required.

Inspired by the pioneering works of Angelillo and Fortunato and Angelillo et al. [34][36], the present paper proposes an innovative and promising parametric approach based on the Membrane Equilibrium Analysis (MEA) [37, 40]. The key idea is to extend the Thrust Line Analysis (TLA), widely used for 2D equilibrium problems concerning arches, to 3D dome or vault equilibrium problems. Equilibrium states of masonry domes can be thought of as carried by an ideal membrane that due to Heyman's assumptions, must be compressed (i.e. the generalized stress is negative semi-definite) and entirely contained within the dome volume. The membrane equilibrium is formulated in Pucher form [41] in terms of two unknown scalar functions, namely the stress potential and the elevation of the membrane. Then, the equilibrium equations are reduced to the transverse equilibrium only by introducing the Airy stress potential function. On adopting a form-finding strategy, the shape on which the membrane stress acts is assumed as unknown in the Pucher equation and tuned by a number of geometric parameters to be optimized. The constrained optimization procedure consists in maximizing the value of the load factor under the unilateral constraints related to the NT material assumption. The lines along which the membrane surface approaches or crosses the limit surfaces of the dome (i.e. the intradox or extrados surfaces) provide candidate lines of hinging at collapse. Such a prediction can be easily cross checked with predictions obtained with experimental results.

The paper is organized as follows: Section 2 provides the mathematical preliminaries on the membrane equilibrium problem and its formulation in terms of Pucher stress, Section 3 presents the proposed parametric procedure and the adopted form-finding strategy, Section 4 gives two trivial application of the proposed method to a hemi-spherical dome with the sole aim of illustrating the method, finally concluding remarks and future prospects are summarized in Section 5. 


\section{MEMBRANE EQUILIBRIUM OF A DOME}

\subsection{Geometry: "a la Monge" description}

Let us consider a masonry dome subjected to its own weight and to the action of horizontal body forces controlled by a load factor $\boldsymbol{\lambda}=\left(\lambda_{1}, \lambda_{2}\right)$ (Fig.1). With respect to a right-hand orthogonal coordinate system $O\left(x_{1}, x_{2}, x_{3}\right)$, the geometry of membrane surfaces can be conveniently represented by a Monge patch:

$$
\left\{\mathbf{x}=\left(x_{1}, x_{2}, f\left(x_{1}, x_{2}\right)\right),\left(x_{1}, x_{2}\right) \in \Omega\right\}
$$

where $f\left(x_{1}, x_{2}\right)$ is, in general, an arbitrary continuous function of its arguments $\left(x_{1}, x_{2}\right)$ and $\Omega$ is the so-called planform of the membrane, namely a connected plane region obtained as projection of the inner or outer membrane surfaces (i.e. $S_{i}$ and $S_{e}$ ) on the $x_{1} x_{2}$-transverse plane.

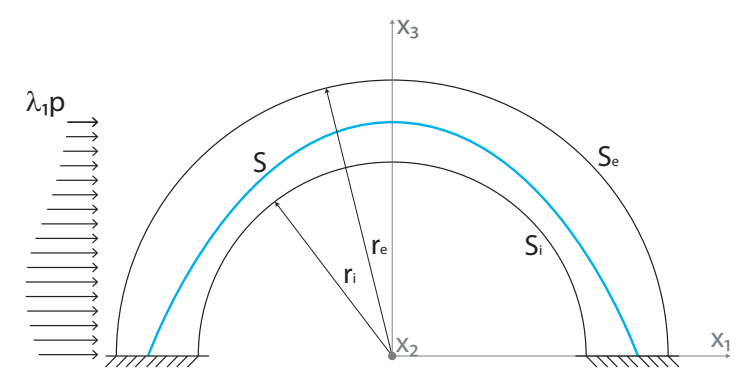

Figure 1: Section of a typical hemispherical dome in the $x_{1} x_{3}$-coronal plane.

The surface forces per unit projected membrane area, applied to the dome are

$$
\mathbf{p}=\left\{\lambda_{1} p, \lambda_{2} p,-p\right\}
$$

where $p=b t J^{*}$ is the dome self-load per unit projected area; $t$ is the dome thickness and $J^{*}$ is the area ratio between the loading surface and the planform. For the sake of simplicity, we suppose that such forces are lumped to a conveniently chosen loading surface $S_{p}$ all contained in the dome thickness.

When the body force $p$ is given, by tuning the load factor $\lambda$ we search for a thrust surface $S$ (i.e. a membrane surface) which carries the applied loads and lays entirely within the limit surfaces $S_{i}, S_{e}$ of the masonry dome and capable of sustaining the applied loads through purely compressive stresses.

\subsection{Equilibrium}

The equilibrium problem of the membrane $S$ subjected to the surface force per unit platform area p can be described through a Differential Geometry (DG) approach [34] based on the Pucher formulation [41] as follow

$$
\left\{\begin{array}{l}
S_{11,1}+S_{12,2}+\lambda_{1} p=0 \\
S_{21,1}+S_{22,2}+\lambda_{2} p=0 \\
S_{11} f_{, 11}+S_{22} f_{, 22}+2 S_{12} f_{, 12}-f_{, 1} \lambda_{1} p-f_{, 2} \lambda_{2} p+p=0
\end{array}\right.
$$


where $S_{i j}$ is the $i j$ Pucher stress component. Hereafter, we use the subscript notation $(*)_{, i}$ to describe the partial differentiation of $(*)$ with respect to $x_{i}$, and the subscript notation $(*)_{, i j}$ to describe the second derivative of $(*)$ with respect to $x_{i}$ and $x_{j}(i, j=1,2)$.

The equilibrium of the Pucher stress in the planform can be solved on introducing a stress potential, in the following way

$$
\left\{\begin{array}{l}
\tilde{S}_{11}=S_{11}+\int \lambda_{1} p d x_{1}=F_{, 22} \\
\tilde{S}_{12}=S_{21}=-F_{, 12} \\
\tilde{S}_{22}=S_{22}+\int \lambda_{2} p d x_{2}=F_{, 11}
\end{array}\right.
$$

were $F\left(x_{1}, x_{2}\right)$ is the so called Airy stress function, which here is assumed to be only continuous (more detailed information with regard to the underlying assumptions can be found in [34]). Based on the Airy solution (4) and setting $h_{i}\left(\lambda_{i}\right)=\int \lambda_{i} p d x_{i}(i=1,2)$, the equilibrium equations (3) reduce to a single linear equation in the unknown stress potential function $F\left(x_{1}, x_{2}\right)$

$$
\left(F_{, 22}-h_{1}\left(\lambda_{1}\right)\right) f_{, 11}+\left(F_{, 11}-h_{2}\left(\lambda_{2}\right)\right) f_{, 22}-2 F_{, 12} f_{, 12}-f_{, 1} \lambda_{1} p-f_{, 2} \lambda_{2} p+p=0
$$

This is a second order Partial Differential Equation (PDE) in which the components of the second fundamental form of the surface $f\left(x_{1}, x_{2}\right)$ represent non-constant coefficients. Depending on the definiteness of the Hessian of the shape function $f$ the equation (5) can be elliptic, hyperbolic or parabolic.

\subsection{Constitutive restrictions}

By assuming a Normal Rigid No-Tension (NRNT) material, the membrane stress tensor $\tilde{\mathbf{S}}$ must be negative semi-definite $\left(\tilde{\mathbf{S}} \in S y m^{-}\right)$(see [34]), namely, in $3 D$ Euclidian space

$$
\operatorname{tr} \tilde{\mathbf{S}} \leq 0 \wedge \operatorname{det} \tilde{\mathbf{S}} \geq 0
$$

These conditions, in terms of the stress function $F\left(x_{1}, x_{2}\right)$ read

$$
F_{, 11}+F_{, 22} \leq 0 \wedge F_{, 11} F_{, 22}-F_{, 12}^{2} \geq 0
$$

which means that the stress surface described by $F\left(x_{1}, x_{2}\right)$ has to be concave.

\section{METHODOLOGY: FORM-FINDING PROBLEM}

By assuming that the shape $f\left(x_{1}, x_{2}\right)$ of the membrane is known, the Boundary Value Problem (BVP) for the unilateral membrane $S$ consists in finding an admissible (i.e. concave) stress function $F\left(x_{1}, x_{2}\right)$ (i.e. compressive membrane stresses) satisfying the equation (5) and either Dirichlet or Neumann boundary conditions:

$$
\left.F\right|_{\partial \Omega}=\left.g \vee \frac{d F}{d n}\right|_{\partial \Omega}=h
$$

where, $\partial \Omega$ is the projected boundary, i.e. the closed boundary of the platform $\Omega ; g\left(x_{1}, x_{2}\right)$ and $h\left(x_{1}, x_{2}\right)$ are the moment and the shear forces generated by applying the projected tractions on a $1 D$ beam with the same form as $\partial \Omega$. In other words, since the PDE (5) is a second-order equation (rather than a fourth-order equation as happens in plane linear 
elasticity) we can choose to prescribe the normal or the tangential component (i.e. $F$ or

$\frac{d F}{d n}$ ) of the stress or even any combination of the two at the projected boundary, in a quite equivalent manner.

At any fixed value of the load factor $\lambda$, the BVP problem formulated in these terms admits a unique solution which, however, disregards the constitutive restrictions (7). Then the equilibrium problem of the unilateral membrane $S$ governed by Pucher's equation (5) can be reduced to a form-finding problem. We search in an assigned n-parameter family of shape functions $f\left(x_{1}, x_{2}, \alpha_{1}, \alpha_{2}, \ldots, \alpha_{n}\right)$, constrained to be entirely contained within the dome volume and such that the Hessian is definite (i.e. a convex polynomial function), the only one that provides a solution of the transverse equilibrium equation (5) which fulfills the BVP as well as the concavity conditions (7). The parameters $\alpha_{i}$ can represent, for example, the size, the position or the asymmetry of the stress membrane $S$. The restriction on the Hessian ensures that transverse equilibrium equation (5) is elliptic and then easy to solve by a FEM-like numerical strategy. Then, to assess the ultimate load capacity of the dome, i.e. the load factor $\lambda$, we can search for the maximum value of $\|\lambda\|$ within the feasible region such that a concave solution of the BVP so defined exists (i.e. $F \in$ Sym $\left.^{-}\right)$.

\section{Numerical applications}

The goal of this section is to illustrate how the method works through two trivial examples. All examples consider a hemispherical dome with thickness-radius ratio $(t / L)$ equal to 0.2 . It is also assumed that, without loss of generality, the horizontal load $\mathbf{p}$ is settled to be constant per projected area and equal to $\{\lambda p, 0,-p\}$ defining the loading surface $S_{p}$ as

$$
S_{p}=\left\{\left(x_{1}, x_{2}, f_{p}\left(x_{1}, x_{2}\right)\right),\left(x_{1}, x_{2}\right) \in \Omega\right\}
$$

where $f_{p}\left(x_{1}, x_{2}\right)$ is the paraboloid (Fig. 2)

$$
f_{p}\left(x_{1}, x_{2}\right)=L\left(1-\frac{x_{1}^{2}+x_{2}^{2}}{t^{2}}\right)
$$

$L$ is the middle radius of the dome.Note that, for convenience purposes, all the geometrical dimensions are adimensionalized with respect to the reference lenght $L$.

Figure 2: Loading surface $S_{p}$

The Pucher's equation governing the equilibrium problem (5) is parametrically solved for the shape $f\left(x_{1}, x_{2}, \alpha_{1}, \alpha_{2}, \ldots\right)$ by using the PDEs tool implemented in Mathematica( (Version 12) [42] and based on a triangular Finite Element discretization (Please refer to [27] for more details).

\subsection{Example 1}

In the first example we choose an initial membrane shape corresponding to the paraboloid (10). This shape is fully contained within the dome thickness but it is not dependent on the geometrical parameters $\alpha_{i}$. The maximum value of $\lambda$ at which the stress ceases to be a negative semi-definite concave surface is $\lambda=0.35$. Fig. 3 shows the principal stresses 


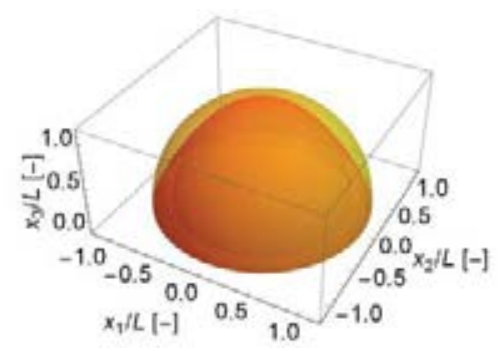

(a)

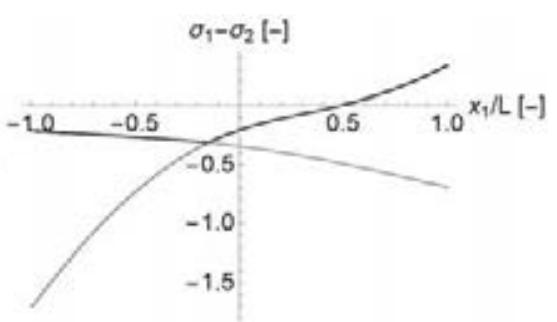

(b)

Figure 3: Thrust surface $S_{p}$ inside the dome (a) and principal stresses profile in the sagittal plane for $\lambda=0.38$ (b)

profile in the $x_{2} x_{3}$-sagittal plane for a value of $\lambda=0.38$ that leads to tensile stresses upwind with respect to the direction of the horizontal force.

In order to optimize the membrane shape $f\left(x_{1}, x_{2}\right)=S_{p}$, we have added to $f_{p}$ a convenient shape function $\Delta f\left(x_{1}, x_{2}, \alpha_{1}, \alpha_{2}, \ldots, \alpha_{n}\right)$, that is a cubic interpolating spline function with an appropriate set of control points $\alpha_{1}, \alpha_{2}, . ., \alpha_{n}$ (i.e. maximum height, middle radius and inflexion point of membrane shape). By numerically solving the parametric equilibrium equation 5 we obtain a class of membrane forms depending on the load factor $\lambda$. By regarding the load factor $\lambda$ as the objective function, the parameters $\alpha_{1}, \alpha_{2}, \ldots, \alpha_{n}$ are finally optimized by maximizing $\lambda\left(\alpha_{1}, \alpha_{2}, \ldots, \alpha_{n}\right)$.

The so optimized membrane shape $f\left(x_{1}, x_{2}, \alpha_{1}, \alpha_{2}, \ldots, \alpha_{n}\right)$ enables a significant increase in the maximum value of $\lambda$ at which the thrust surface is contained entirely inside the dome and conditions (7) hold, namely $\lambda=0.42$.

Fig. 4 shows the corresponding profile of the principal stresses corresponding to the optimized solution in the $x_{1} x_{3}$-coronal and in the $x_{2} x_{3}$-sagittal planes. The contour plot of the principal (minimum and maximum) projected stress values and the corresponding isostatic lines are also reported.

\subsection{Example 2}

In this example we analyze a dome which displays a certain pattern of crack, due to horizontal actions which exceed the limit value. In such a case the stress membrane is not contained entirely in the dome (Figs. 5). Therefore, we allow for a small enlargement of the extrados surface and look for the intersection of the membrane surface with the original extrados surface $S_{e}$. In this case, the maximum load factor such that the stress is negative semi-definite is $\lambda=0.45$. The contour plot of the minimum and maximum principal stresses and the corresponding isostatic lines are reported in Figs. 5, in particular the maximum principal stress almost vanish for $x_{1} \in(-17,-5)$, leeward with respect to the horizontal action. Notice that the isostatic lines corresponding to zero principal stresses, are almost straight, meaning that the surface profile in such directions consists of funicular lines. In Fig. 5b the profile of the curve of intersection of the optimized membrane surface with the original extrados surface $S_{i}$ is shown (black lines).

\section{CONCLUDING REMARKS}

This paper presents a new parametric approach, based on the Membrane Equilibrium Analysis, to the assessment of the load carrying capacity of masonry domes or vaults under horizontal body forces. By using the MEA the load applied to a dome composed of 


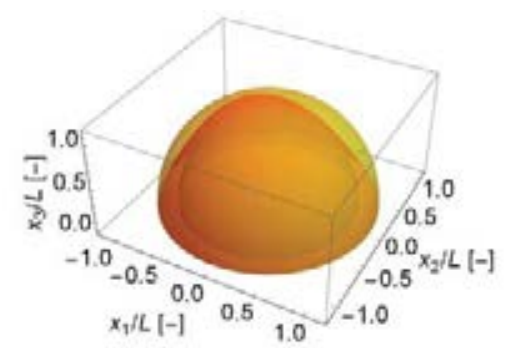

(a)

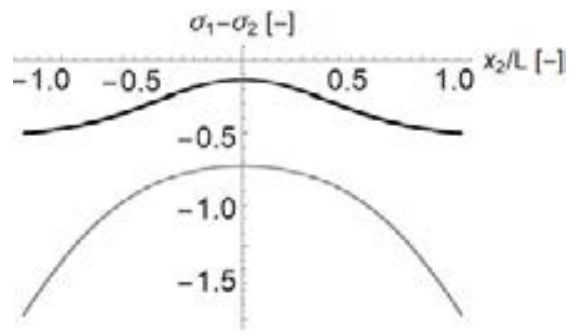

(c)

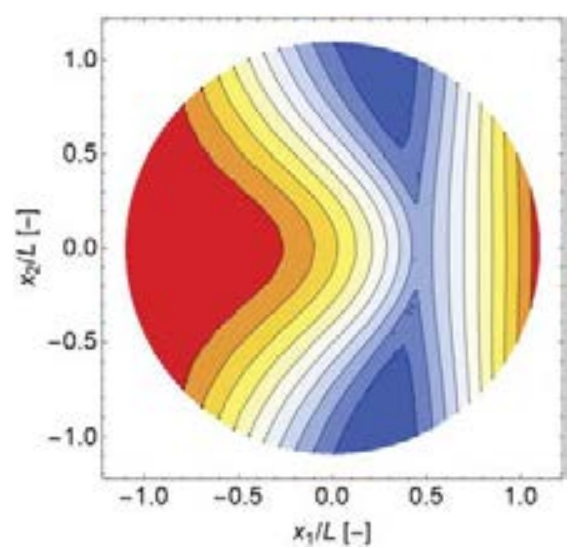

(e)

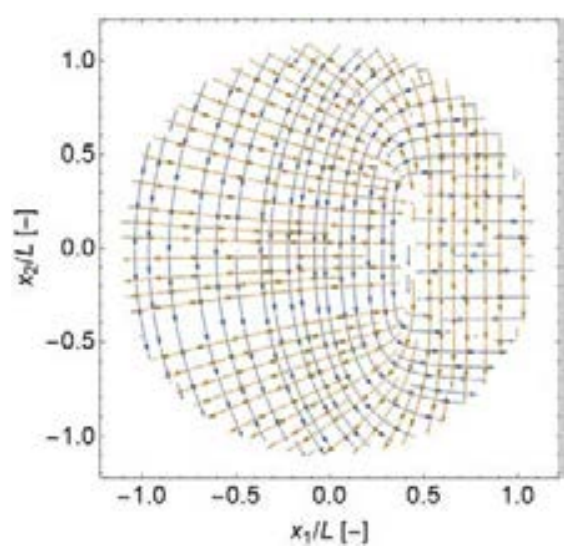

(b)

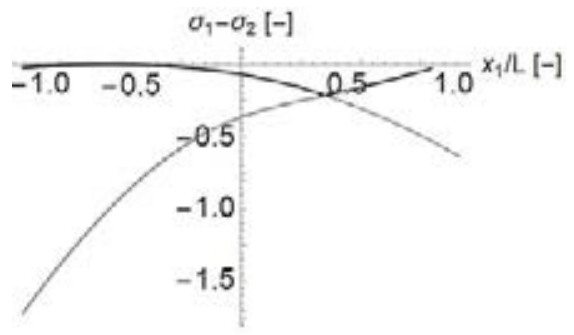

(d)

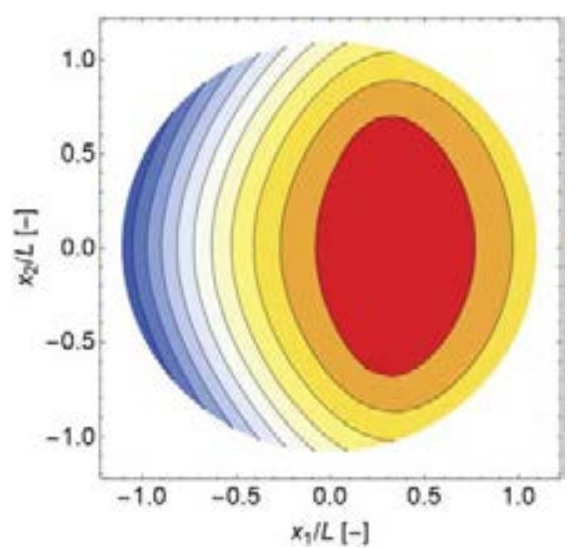

(f)

Figure 4: Optimized thrust surface $S$ corresponding to the optimal value of $\lambda$ (a); principal lines of curvature (b); principal stress profile in the coronal plane (c); principal stress profile in the sagittal plane $(\mathrm{d})$; contour plot of minimum and maximum principal projected stress values $(e, f)$

unilateral Heyman material is lumped to a loading surface $S_{p}$ and is carried by a thrust surface $S$ contained inside the masonry. By changing its shape $f$ through the tuning of a finite number of geometric parameters, the generalized membrane stress balancing the loads as well as its projection on the planform change. The optimal value of the geometric parameters, i.e. the optimal shape function of the stress membrane, is obtained by maximizing the horizontal load multiplier $\lambda$, with the constraints that the generalized stress is non-positive definite, the surface $S$ is fully contained inside the dome volume and the Hessian of the shape function $f$ is positive definite (i.e. $f$ belongs to a n-parameter 


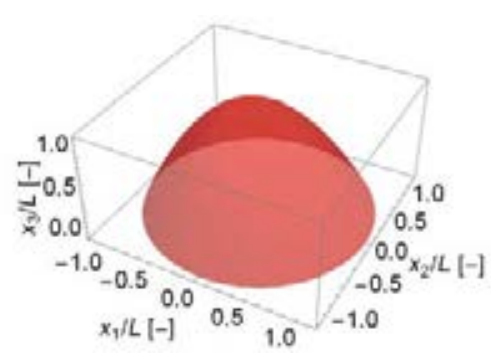

(a)

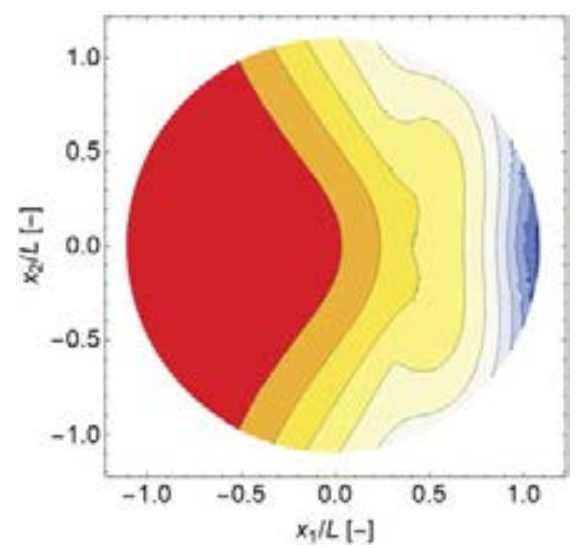

(c)

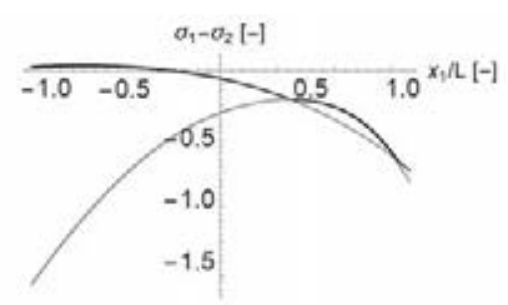

(e)

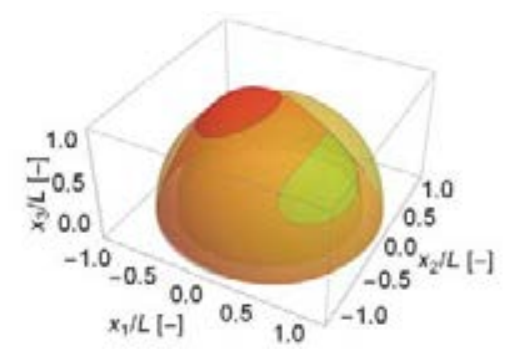

(b)

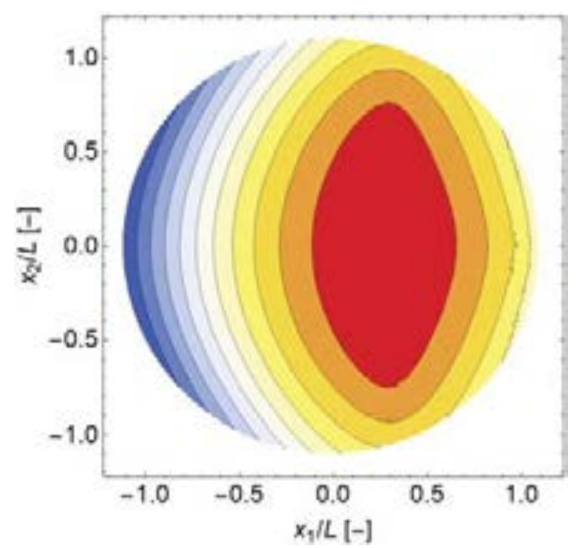

(d)

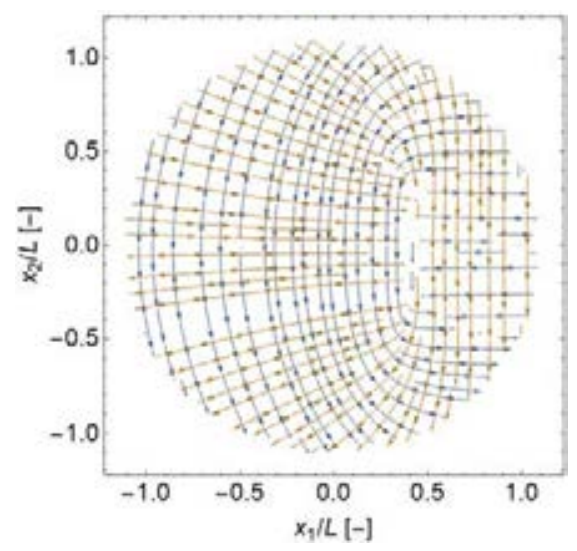

(f)

Figure 5: Optimized thrust surface $S$ (a); thrust surface $S$ partially inside the dome (b); contour plots minimum and maximum principal projected stress values contour plot $(\mathrm{c}, \mathrm{d})$; principal stress profile in the sagittal plane (e); isostatic lines corresponding to projected principal stress values (f).

function family of convex polinomia). The latter condition guarantees that the Pucher's equilibrium equation is elliptic and then easy to solve though a FEM-like numerical strategy. The proposed approach can be applied to either design or assessment of ultimate load capacity and can be easily extended to more complex geometries (i.e. thin-thick, flatted or pointed domes and semi-circular, cross, Rib or Fan vaults) even though it needs a substantial effort in terms of implementation. 


\section{FUNDING}

This work was supported by the Italian Ministry of Education, University and Research (MIUR) under the "Departments of Excellence" grant L.232/2016.

\section{REFERENCES}

[1] O’Dwyer, D.W. Funicular analysis of masonry vaults. Computers and Structures, 73(1-5), 187-197, 1999.

[2] Block P., Ciblac T., Ochsendorf J., Real-time limit analysis of vaulted masonry buildings. Computers and Structures, 84(29), 1841-1852, 2006.

[3] De Lorenzis, L., DeJong, M.J. and Ochsendorf, J. Failure of masonry arches under impulse base motion. Earthquake Engineering and Structural Dynamics, 36(14), 2119-2136, 2007.

[4] Mallardo, V., Malvezzi, R., Milani, E., and Milani, G. Seismic vulnerability of historical masonry buildings: A case study in Ferrara. Engineering Structures, 30, 22232241, 2008.

[5] DeJong, M.J. Seismic Assessment Strategies for Masonry Structures, PhD dissertation Building Technology at the Massachusetts institute of technology, 2009.

[6] Foraboschi, P. Resisting system and failure modes of masonry domes. Engineering Failure Analysis, 44, 315-337, 2014. DOI: 10.1016/j.engfailanal.2014.05.005

[7] Khan M.A., Paul D.K. Seismic Performance of Masonry Arches and Vaults. In: Rodrigues H., Elnashai A., Calvi G. (eds) Facing the Challenges in Structural Engineering. GeoMEast 2017. Sustainable Civil Infrastructures, Springer, Cham, 2018. DOI: 10.1007/978-3-319-61914-9_3

[8] Iannuzzo, A., Olivieri, C., and Fortunato, A. Displacement capacity of masonry structures under horizontal actions via prd method. Journal of Mechanics of Materials and Structures, 14(5), 703-718, 2019. DOI:10.2140/jomms.2019.14.703

[9] Mascolo, I., Fulgione, M., Pasquino M. Lateral torsional buckling of compressed open thin walled beams: experimental confirmations. Int. J. Masonry Research and Innovation, 4(1/2), 150-158, 2019. DOI: 10.1504/IJMRI.2019.096829

[10] Chetouane, B., Dubois, F., Vinches M. and Bohatier, C. NSCD discrete element method for modeling masonry structures. International Journal for Numerical Methods in Engineering, 64, 65-94, 2005.

[11] Lemos, J.V. Numerical issues in the representation of masonry structural dynamics with discrete elements. In M. Papadrakakis, D.C. Charmpis, N.D. Lagaros, Y. Tsompanakis (Eds.), ECCOMAS Thematic Conference on Computational Methods in Structural Dynamics and Earthquake Engineering. Crete, Greece, 2007.

[12] Malena, M. and Casciaro, R. Finite element shakedown analysis of reinforced concrete 3D frames. Computers and Structures, 86, 1176-1188, 2008. 
[13] Lucchesi, M., Padovani, C., Pasquinelli, G. and Zani, N. Masonry constructions: mechanical models and numerical applications. Lecture Notes in Applied and Computational Mechanics, 39, Springer, Berlin, 2008.

[14] de Felice, G., Amorosi, A. and Malena M. Elasto-plastic analysis of block structures through a homogenization method. J. Numer. Anal. Meth. Geomech., 34, 221-247, 2010 .

[15] de Felice, G., and Malena M. Failure pattern prediction in masonry. J. Mech. Mater. Struct., 14, 663-682, 2019.

[16] Gobbin, F., de Felice G. and LEmos, J.V. A discrete element model for masonry vaults strengthened with externally bonded reinforcement. Int. J. Archit. Herit., 114, 2020. DOI: $10.1080 / 15583058.2020 .1743792$

[17] Paris, V., Pizzigoni, A. and Adriaenssens, S. Statics of self-balancing masonry domes constructed with a cross-herringbone spiraling pattern. Engineering Structures, 215, 110440, 2020. DOI: 10.1016/j.engstruct.2020.110440

[18] Rossi, M., Calderini, C., Lagomarsino, S. and Milani, G. Seismic response of masonry vaulted structures: experimental and numerical modelling. in Lourenço, P. B., Haseltine, B. A., and Vasconcelos, G. (eds) 9th International Masonry Conference. Guimarães: Universidade do Minho, 2014.

[19] Rossi, M., Calderini, C. and Lagomarsino, S. Experimental testing of the seismic in-plane displacement capacity of masonry cross vaults through a scale model. Engineering Structures, 123, 300-312, 2016.

[20] Milani, G., Rossi, M., Calderini, C. and Lagomarsino, S. Tilting plane tests on a small-scale masonry cross vault: Experimental results and numerical simulations through a heterogeneous approach. Bulletin of Earthquake Engineering, 14(1), 261281, 2016. DOI: $10.1007 / \mathrm{s} 10518-015-9815-1$

[21] Barsotti, R., Bennati, S., Ochsendorf, J.A. and Tirabasso C. Scale models for the experimental analysis of the collapse mechanisms of masonry bay windows under horizontal actions. in COMPDYN 2017. Proceedings of the 6th ECCOMAS Thematic Conference on Computational Methods in Structural Dynamics and Earthquake Engineering, 15 June 2017 through 17 June 2017, Rhodes Island, Greece, 2017.

[22] Huerta, S. Arcos bóvedas y cúpulas. Geometría y equilibrio en el cálculo tradicional de estructuras de fábrica. Madrid : Instituto Juan de Herrero, 2016.

[23] Angelillo, M. Practical applications of unilateral models of masonry equilibrium. in Angelillo M. (ed.) Mechanics of masonry structures, Springer, Vienna, 109-210, 2014.

[24] De Chiara E., Cennamo C., Gesualdo A., Montanino A., Olivieri C., Fortunato A. Automatic generation of statically admissible stress fields in masonry vaults. Journal of Mechanics of Materials and Structures, 14(5), 719-737, 2019.

[25] Fraddosio A., Lepore N., Piccioni M.D. Lower Bound Limit Analysis of Masonry Vaults Under General Load Conditions. RILEM Bookseries, 2019. DOI:10.1007/9783-319-99441-3_118. 
[26] Gesualdo A., Brandonisio G., De Luca A., Iannuzzo A., Montanino A. and Olivieri C. Limit analysis of cloister vaults: the case study of Palazzo Caracciolo di Avellino. Journal of Mechanics of Materials and Structures, 14(5), 739-750, 2019.

[27] Olivieri C., Angelillo M., Gesualdo A., Iannuzzo A. and Fortunato A. Parametric design of purely compressed shells, Mechanics of Materials, 155, 103782, 2020 DOI: 10.1016/j.mechmat.2021.103782

[28] Olivieri C., Fortunato A., DeJong M. A new equilibrium solution for masonry railway bridges: the case study of Marsh Lane Bridge. Int. J. of Masonry Research and Innovation, 2021. (In press) DOI: 10.1504/IJMRI.2021.10037557

[29] Mascolo I., Gesualdo, A., Olivieri C., Fortunato A. On rigid blocks detection in unilateral masonry-like structures: a continuous displacement fields approach. Int. J. of Masonry Research and Innovation, 2021. (In Print)

[30] Malena M., Angelillo M., Fortunato A., de Felice G., Mascolo I., Arch bridges subject to pier settlements: continuous vs. piecewise rigid displacements methods. Meccanica, 2021. (Under Review)

[31] Fortunato, A., Gesualdo, A., Mascolo I. and Monaco, M. P-Bézier energy optimization for elastic solutions of masonry-like panels. Int. J. of Masonry Research and Innovation, 2021. (In Press) DOI: 10.1504/IJMRI.2021.10037508

[32] Heyman, J. The stone skeleton. Cambridge University Press.

[33] Zienkiewic, O.C., Valliappan S., King I.P., Stress analysis of rock as a 'No Tension' material. Géotechnique, 18(1), 56-66, 1968.

[34] Angelillo M., Fortunato A. Equilibrium of masonry vaults. in Lecture notes in applied and computational mechanics, novel approaches in civil engineering, Berlin: Springer, 14, (Fremond M, Maceri F Eds), 2004.

[35] Angelillo, M., Babilio, E., and Fortunato, A. Singular stress fields for masonry-like vaults. Continuum Mechanics and Thermodynamics, 25, 423-441, 2013.

[36] Angelillo, M., Babilio, E., Fortunato, A., Lippiello, M., Montanino, A. Analytic solutions for the stress field in static sandpiles. Mechanics of Materials, 95, 192-203, 2016

[37] ABlock P., Ochsendorf J. Thrust network analysis: a new methodology for threedimensional equilibrium. Shell. Spat. Struct., 48(155), 167-173, 2007

[38] Briccola D., Bruggi M., Analysis of 3D lineelastic masonry-like structures through the API of a finite element software. Adv. Eng. Softw., 133, 60-75, 2019

[39] Liew A., Avelino R. , Moosavi V., Van Mele T., Block P., Optimising the load path of compression-only thrust networks through independent sets. Structural and Multidisciplinary Optimization, 60, 231-44, 2019

[40] Bruggi M., A constrained force density method for the funicolar analysis and design of arches, domes and vaults. Int. J. Solids Struct., 193-194, 251-69, 2020 
[41] Pucher, A. Uber der spannungzustand in gekrummten flachen. Beton u Eisen, 33, 298-304, 1934.

[42] Wolfram S. The Mathematica Book, 5th ed., Wolfram Media, 2003. 